\title{
DEBATE
}

\section{A defence of the potential future of value theory}

\section{Marquis}

\begin{tabular}{|c|c|}
\hline & J Med Ethics 2002;28:198-201 \\
\hline $\begin{array}{l}\text { Correspondence to: } \\
\text { Professor D Marquis, } \\
\text { Department of Philosophy, } \\
1445 \text { Jayhawk Blvd, Room } \\
\text { 3090, The University of } \\
\text { Kansas, Lawrence, Kansas } \\
66045-7590 \text {, USA; } \\
\text { dmarquis@ku.edu } \\
\text { Revised version received } \\
4 \text { February } 2002 \\
\text { Accepted for publication } \\
14 \text { February } 2002\end{array}$ & $\begin{array}{l}\text { In this issue of the journal Mark Brown has offered a new argument against my potential future of value } \\
\text { theory. I argue that even though the premises of this new argument are far more defensible than the } \\
\text { premises of his old argument, the new argument does not show that the potential future of value theory } \\
\text { of the wrongness of killing is false. If the considerations to which Brown appeals are used, not to show } \\
\text { that the potential future of value theory is false, but to show that abortion is morally permissible, they } \\
\text { are also unsuccessful. I also argue that Brown's clarified self-represented future of value account and } \\
\text { Simon Parsons's account of the wrongness of killing are both subject to major difficulties. Finally, I } \\
\text { show, in an appendix, that Brown's assertion that my discussion of his views suffers from major logical } \\
\text { errors is false. }\end{array}$ \\
\hline
\end{tabular}

k my 1989 essay on abortion I assumed that it is wrong to kill adults and children, except in unusual circumstances. I argued that the best account of the wrongness of killing adults and children is that killing us deprives us of our valuable futures, of all of the goods of life that we would have experienced if we had lived out our natural life spans. On the assumption that the wrongness of abortion stands or falls on the moral standing of the fetus, it follows that abortion is wrong, for abortion deprives a fetus of a future like ours.'

In his 2000 essay in this journal Mark Brown offered the following argument against my account of the wrongness of killing, which he called "the potential future of value view". ${ }^{2}$ Premise 1: If having a potential future of value is the basis for the right not to be killed, then humans have a welfare right to what they need to stay alive.

Premise 2: Humans do not have welfare rights to what they need to stay alive.

Conclusion: Having a potential future of value is not the basis for the right not to be killed. ${ }^{3}$

In a 2001 essay in this journal I responded to Brown's criticism by offering reasons for thinking that the potential future of value account (or any other account) of the wrongness of killing does not, by itself, entail anything about welfare rights at all and that therefore, Brown's first premise is false. ${ }^{4} \mathrm{I}$ also argued that Brown's skepticism concerning welfare rights is not accepted by most people. ${ }^{5}$ Since both premises of Brown's argument are dubious, I concluded that Brown had not shown that the potential future of value theory is false.

In his essay in this issue of the journal Brown has offered a new argument.

Premise 1: If having a potential future of value is the basis for a right not to be killed that is sufficiently strong to protect the fetus in utero, then humans have welfare rights to the bodily integrity of other persons.

Premise 2: Humans do not have welfare rights to the bodily integrity of other persons.

Conclusion: It is false that having a potential future of value is the basis for a right not to be killed that is sufficiently strong to protect the fetus in utero. ${ }^{6}$

Brown's new argument is both very different from, and a vast improvement on, Brown's old argument. The new first premise is plainly true. Furthermore, Brown has traded in a second premise that would be rejected by most people for a different second premise that, under its most obvious interpretation, is clearly true. The price paid for these advan- tages is, however, very high. Even if both of Brown's new premises are true, Brown's new argument does not show that the potential future of value theory is false. All it shows is that the potential future of value theory, even if true, does not, by itself, entail a fetal right to her mother's uterus. Brown is clearly right. I made it clear that I endorsed such a view in the essay to which Brown is responding. ${ }^{7}$

Suppose Brown would agree that he has not shown that the potential future of value theory is false and therefore he has not shown that fetuses lack the right to life. We could understand him to be claiming that, even if fetuses do have the right to life, because humans do not have the right to the bodily integrity of other persons, abortion is morally permissible. ${ }^{8}$

This new argument is subject to major problems, just because its conclusion is different. If fetuses have the right to life, then, from a moral point of view, they are just like us, only younger. They are children. They have parents. Parents have very serious obligations regarding the wellbeing of their children. Abortion involves not just killing a child, but killing one's own child. It involves withdrawing her nutrients, that is, starving one's child to death. Such actions seem not merely wrong; they seem abhorrent.

Now we are in a position to understand the advantages of Brown's old argument with its dubious premises. The old argument was designed to show that the potential future of value theory was false. If Brown had been correct, then one could then argue that since there is no other basis for attributing to a fetus the right to life, fetuses lack the right to life. As a consequence fetuses belong to a moral category entirely different from adults or children. It follows that anti-choice talk about murdering the unborn and starving one's own children can be confidently rejected.

Brown's new argument is, however, entirely compatible with a fetal right to life that is as robust as yours and mine. Given such a right, talk about starvation and killing one's children is not at all absurd. There is a lesson to be learned from this. One reason that the abortion issue is so difficult (and so interesting) is that, on the condition that fetuses have the right to life, there are powerful intuitions that support each side of the dispute. On the one side, as Brown correctly argues, persons have the right to control their own bodies. On the other side, for parents to starve their own children is abhorrent. On the one side, we can think of a pregnancy as a bodily intrusion to which a woman did not consent. We can think of it, as Brown points out, as like rape. On the other side, we can think of abortion as killing one's own child. Such a 
clash will not be resolved, as Brown would have it, by considering only one set of intuitions. ${ }^{9}$ It will be resolved, as I pointed out in my 2001 essay, only by sustained moral analysis. ${ }^{10}$ It follows that an argument based on the considerations that Brown presents is not sufficient for showing the moral permissibility of abortion.

\section{BROWN'S CLARIFIED SELF-REPRESENTED FUTURE OF VALUE THEORY}

If the argument of the preceding section is sound, then prochoicers have an interest in finding an alternative account of the wrongness of killing that is incompatible with a fetal right to life. In his 2001 essay Brown defended a selfrepresented future of value (henceforth, SRFOV) theory as such an alternative. In my reply to Brown I argued that Brown's SRFOV theory of the wrongness of killing is ambiguous and is, on any interpretation, unsound.

Brown's clarified SRFOV view that he defends in this issue of the journal is an improvement over his old SRFOV view because Brown has removed some, but not all, of the ambiguities surrounding his old view. Some distinctions are needed for a clear discussion of his clarified view.

Quite a few writers on abortion have claimed that depriving an individual of her future life is wrong because it deprives her of something she greatly desires or of something she greatly values or of something she greatly cares about. ${ }^{11}$ Since most of us greatly value the goods of our future lives, such an account seems plausible. Since respecting the desires of others seems to be a basic feature of morality, such an account seems morally relevant. Furthermore, this account has the convenient feature of explaining why abortion is morally permissible, for fetuses are neurologically incapable of valuing their future lives. This point can be put in SRFOV language by saying that killing us deprives us of what our self-represented futures of value, that is our hopes and dreams, are representations of.

When I wrote my 2001 essay I believed that it was possible (but far from certain) that Brown held this future oriented view. Some of his remarks suggested that he did hold it. It seemed to me more plausible than any other interpretation of his view. The view is sufficiently plausible that other prochoice philosophers have adopted a view much like it. However, in his 2002 essay Mark Brown categorically denies that he did hold or does hold a future oriented SRFOV view. "Plainly, on the intended interpretation, self-represented futures refer to present events occurring within the mind of a person.."12

Alas, Brown's interpretation does not remove the ambiguities from his SRFOV view. Events endure through time. Brown's reference to a present event might be a reference either to the present time slice of an enduring event or to an enduring event, one of whose time slices is in the present. Consider the former interpretation. An argument in my 2001 essay shows that it is impossible to deprive someone of the present time slice of one of her mental events. To deprive someone of something is to cause her not to have that thing. It is necessarily true that I have the mental events that I presently have. It follows that to cause me not to have now what I have now is incoherent. Because this interpretation of Brown's view is self-contradictory, we should not attribute it to Brown unless we have to

There is a more plausible, but less literal, interpretation of Brown's view. On this interpretation when Brown refers to a present event, he is referring to an enduring event, one of whose stages exists at the present time. This reflects the way we talk. Often when we talk of being deprived of what we have at present, we do not really mean to say that we are deprived now of what we have now. We mean that we will be deprived in the future of something one of whose stages exists at the present time. In this case, we think of what we have at present as an enduring thing. To be deprived of what we have at present means that we will not be allowed (in the future) to continue to enjoy what we have (now). Thus, for me to be deprived of my (present) hopes and dreams is, on this more plausible present interpretation of the SRFOV view, for me to be deprived in the future of the same hopes and dreams that I have now and which would continue into the future were I not soon to be deprived in one way of another. I shall call this a plausible present SRFOV view in order to contrast it with the former implausible present SRFOV view and in order to retain Brown's language.It is important, however, to be clear that although the deprivation in question is of an enduring thing that I presently possess, the deprivation must occur in the future.

The great advantage of this plausible present interpretation of the SRFOV view is that it is not subject to same the easy refutation that proved the undoing of the implausible present interpretation. It is still, however, subject to a difficulty. Suppose that in the next five seconds I will change my hopes and dreams in a fairly radical way. Perhaps I am Saul on the road to Damascus. Would it then be permissible to kill me in the next few seconds because I would not be deprived of the hopes and dreams I have now? Surely not. What this shows is that it makes not a particle of difference, from a moral point of view, whether the hopes and dreams of which I would be deprived in the future are the same as, or different from, the hopes and dreams I presently have. This shows that the plausible present SRFOV view is wrong. This drives us to the view that what makes killing me wrong is that it deprives me of the hopes and dreams I would have had at a future time whether they are the same as my present hopes and dreams or not. The present is irrelevant. Call this a future hopes and dreams view. This future hopes and dreams view is not the same as the future SRFOV view that Brown insists he does not hold. The future hopes and dreams view is the view that killing me is wrong because it deprives me of having the hopes and dreams I would have had in my future, not that killing is wrong because it deprives me of the fulfilment of my present hopes and dreams concerning my future life.

There are two big problems with the future hopes and dreams view. First, consider the matter from Brown's point of view. According to the future hopes and dreams view, killing a fetus is wrong because it deprives that fetus of its future hopes and dreams. Therefore, the future hopes and dreams view underwrites a fetal right to life. Alas, the trouble with the future hopes and dreams view, from Brown's point of view, is that it fails to support the moral permissibility of abortion.

Second, the future hopes and dreams view does not focus on what is important to us. I am now writing a paper about the morality of abortion. I hope to finish it. What is important to me is not that I continue to hope to finish it, but that I finish it. If what were important to me were that I continue to hope to finish it, then I would be better off if I never finish it! For if I finish it, I can no longer hope to finish it. The future hopes and dreams view seems to imply that finishing it would be bad for me because it would deprive me of my hope of finishing it. Plainly this is absurd. Thus, the future hopes and dreams account of the wrongness of killing does not get at what is important about our lives, but surely an account of the wrongness of killing should focus on what is most important about our lives. Brown's still ambiguous SRFOV view must be judged a failure, whatever version one chooses.

\section{PARSONS'S ACCOUNT OF THE WRONGNESS OF KILLING}

In this issue Simon Parsons offers a different alternative to the potential future of value account of the wrongness of killing. Parsons believes, if I understand him correctly, that no killing is wrong because of anything having to do with the victim's future. "First, if one believes in the afterlife, death in fact should be more desirable than life. If you believe once you are dead you cease to exist, death cannot be undesirable as it is 
simply non-existence." ${ }^{13}$ Parsons's first claim would certainly surprise Dante, but never mind that. Parsons's second claim merits brief discussion.

Suppose there is no afterlife. On the one hand, once I am dead, there is no me. If there is no me, then the state of being dead cannot be bad for me. ${ }^{14}$ So far so good for Parsons. On the other hand, a life that contains more goods is better than a life that contains fewer goods. Therefore, a shorter life will typically be worse than a longer life because a shorter life typically will contain fewer goods than a longer life. I hold this view. This is why death is a bad thing for us. ${ }^{15}$

Parsons evidently believes that because the state of death cannot be bad for me, the wrongness of killing must reside in events within my life. So he says that killing causes one to be in a state of dying and a state of dying is a misfortune "because the present state of mind one is in becomes undesirable in this manner" ${ }^{16}$ When one is dying and knows it, one has fewer and less hopeful self-representations of a future of value. Therefore, dying harms one. Killing causes dying. Therefore, killing is wrong.

Parsons's account of the wrongness of killing does not explain how someone who has been killed instantaneously and unexpectedly has been victimised. It does not explain how infants have been wronged by being killed. It does not account for the misfortune of someone who dies unexpectedly in her sleep or when in a coma. For Parsons a necessary condition of someone being a murder victim or suffering the misfortune of premature death is that they realise correctly that they are dying.

Parsons sees this problem and goes on to argue that in the cases of these apparent counterexamples to his view the felt loss to the survivors accounts for the wrongness of the killing or the misfortune of premature death. This is of scant comfort to those whose survivors would like to see them out of the way, to the man whose wife is desperately unhappy with him and who would like to avoid splitting the property in a divorce settlement, to the infant who is strangled and abandoned in a trash can. Any account of the wrongness of killing must account for how murder victims are-well-victims. Any account of the wrongness of killing must account for why premature death is a misfortune to the one who dies. Parsons's account fails for these reasons.

\section{CONCLUSION}

Those who wish to defend the prochoice view have two kinds of arguments open to them. (1) They can argue that fetuses lack the right to life. (2) They can argue that even if fetuses have the right to life, they do not have the right to use the body of another without her consent and therefore abortion is morally permissible. Arguments in favor of (1) will (a) attempt to undermine those accounts of the right to life that extend the right to life to fetuses and (b) offer accounts of the right to life that are incompatible with a fetal right to life. Brown's old arguments belonged to categories (la) and (lb). In my 2001 essay I showed that there were many problems with those arguments. Brown's arguments in this issue belong to categories ( $1 \mathrm{~b})$ and (2). Parsons's arguments in this issue belong to category (lb). I have given reasons for thinking that those category ( $\mathrm{lb}$ ) accounts are subject to major difficulties.

The nice thing (from the prochoice point of view) about category (1) arguments is that, if successful, they render the moral permissibility of abortion utterly unproblematic. Brown's category (2) arguments lack this nice feature. Brown appeals to a set of moral intuitions that do indeed support the moral permissibility of abortion. Unfortunately, there are moral intuitions that push us strongly in the opposite direction. Therefore, Brown's arguments in category (2) are inconclusive.

I have not examined all of the difficulties with all of the possible variants of Brown's SRFOV theory. Furthermore, it is not possible in a note of this length to provide either a full-scale defence of the potential future of value theory of the wrongness of killing or the view that abortion is wrong. All I have attempted is a response to certain objections to my views.

\section{APPENDIX: BROWN'S LOGICAL ERRORS}

In the appendix of his essay in this issue of the journal, Brown accuses me of making two errors of logic in my 2001 essay. Since most of the readers of this journal are not philosophers and since Brown is, readers may believe that Brown's pronouncements concerning logic are correct. Quite the contrary. Not correcting Brown's errors would be a disservice to the readers of this journal.

Modus tollens is the valid argument form

If $\mathrm{p}$, then $\mathrm{q}$.

It is false that q.

Therefore, it is false that $\mathrm{p}$.

Brown's old argument against the potential future of value account was an argument of that form. I claimed that Brown's argument suffered from a major internal problem. The internal problem was that any reason to believe that one of the premises of his argument is true is a reason to believe the other is false. Brown objected to my claim because "This is true, but it is a perfectly general logical feature of any argument of the form modus tollens" ${ }^{17}$

Brown's objection is false. If it were true, then the major argument of his 2000 essay, which has the form modus tollens, could not be known to be sound because of the form of the argument. Thus, either he would have to withdraw the argument of that essay or admit to flagrant inconsistency. This should not be an appetising alternative. Fortunately for Brown, however, his objection to modus tollens is not true. Brown offers no argument whatsoever for his exceedingly odd thesis. It is supported, I am sure, by no reputable logic text.

If Brown's objection were true, then no argument of the form modus tollens could be known to be sound. There are medical reasons for thinking that many arguments of the form modus tollens are known to be sound. Modus tollens is an essential part of differential diagnosis. Differential diagnosis, as all physicians know, consists of determining the cause (or in some cases causes, but let's keep it simple) of the symptoms of particular patients. It involves surveying the possible causes of those symptoms and ruling out all but one of the possible causes and confirming the presence of one of the possible causes. Modus tollens is used to rule out possible causes as in the following common example. A patient presents in the emergency room with chest pain. You reason: If this patient's chest pain is due to a myocardial infarction (p), then his cardiac enzymes will be elevated (q). His cardiac enzymes are not elevated (not-q). Therefore, this patient's chest pain is not due to myocardial infarction (not-p). (So you don't admit him). If Brown were correct, reasoning of this kind, which is essential to differential diagnosis, would be unsound. As all physicians know, it is not unsound. Therefore, Brown's view of modus tollens is not correct. (Notice that this argument also had the form of modus tollens.)

Brown also accuses me of what he calls the denial of conjunction fallacy on the basis of the following passage that he quotes from my essay:

If one considers only the victim, then all individuals having a right not to be killed also have a welfare right to be provided with what they need to stay alive. Now add Brown's claim that there is no welfare right to be provided with what one needs to stay alive. It follows that no one has the right not to be killed! ${ }^{18}$ 
Brown and I agree that one can separate out the "if" clause of this argument (although for different reasons). Once that is done Brown claims that the argument has the following form: It is true that both $\mathrm{Q}$ and $\mathrm{R}$

$\mathrm{Q}$ is false.

Therefore, $\mathrm{R}$ is false.

He calls arguments of this form denial of conjunction. He claims that arguments of this form are fallacious. Both of Brown's claims are false.

For reasons that may seem technical to the average reader, arguments of the form denial of conjunction are valid. Here is why. The standard definition of validity is: an argument is valid if and only if it cannot be the case that the premises are all true and the conclusion false. Since the first premise asserts that Q is true and the second premise asserts that Q is false, the premises are self-contradictory. Therefore, the premises of this argument cannot all be true. If the premises of an argument cannot all be true, then it cannot be the case that the premises are all true and the conclusion false. It follows that the argument is valid. Therefore, denial of conjunction is not a fallacy.

There is another reason why Brown's analysis is wrong. Brown has symbolised the argument incorrectly. The argument (with the "if" clause separated out) has the form:

All individuals having the property $\mathrm{S}$ are individuals having the property $\mathrm{P}$.

No individual has the property $\mathrm{P}$.

Therefore, no individual has the property $\mathrm{S}$.

This argument is intuitively valid. Surprisingly, it is not valid in traditional logic. (This is because of a doctrine called existential import that has been discarded in modern logic. For further explanation, ask your local logician.) In standard modern predicate logic, however, the first premise of the argument would be understood, not as a conjunction, but as a universal conditional: if any individual has the property $S$, then that individual has the property P. The argument can be shown to be valid in standard modern predicate logic. The proof is simple, but too technical for non-philosophers. If you are curious, again, ask your local logician.

\section{ACKNOWLEDGEMENT}

I thank Ron Stephens and Teresa Robertson for help with this essay.

\section{REFERENCES AND NOTES}

1 Marquis D. Why abortion is immoral. The Journal of Philosophy 1989;86:183-202. See the second paragraph for the statement of the assumption

2 Brown $M$. The morality of abortion and the deprivation of futures. Journal of Medical Ethics 2000;26:103-7.

3 See reference 2: 104.

4 Marquis D. Deprivations, futures and the wrongness of killing. Journal of Medical Ethics 2001;27:363-9. Compare Brown M. A future like ours revisited. Journal of Medical Ethics 2002;28:192-5 at p. 192 where he baldly asserts the opposite.

5 Marquis D. Deprivations, futures and the wrongness of killing. Journal of Medical Ethics 2001;27:363-9.

6 See reference 4: Brown M: 193.

7 See reference 5: 364 .

8 This seems a reasonable interpretation of Brown's views at reference 4: 194-5.

9 Note Brown's discussion at reference 4: 194.

10 See reference 5: 368 .

11 For example, Singer P. Practical ethics. Cambridge: Cambridge University Press, 1979: 82-3. Reiman J. Abortion and the way we value human life. Lanham: Rowman and Littlefield, 1999. Tooley M. Abortion and infanticide. Philosophy and Public Affairs 1972;2:37-65. Tooley's view is the most famous view of this kind.

12 See reference 4: Brown M: 194.

13 Parsons S. Present self-represented futures of value are a reason for the wrongness of killing. Journal of Medical Ethics 2002;28:196-7.

14 This famous argument is due to Epicurus. Letter to Menoeceus. In: Saunders JL, ed. Greek and Roman philosophy after Aristotle. New York: The Free Press, 1966:49-52.

15 Far more extensive discussions of this issue can be found in Nagel T. Mortal questions. Cambridge: Cambridge University Press, 1979: ch 1. Death, and in Feldman F. Confrontations with the reaper: a philosophical study of the nature and value of death. New York: Oxford University Press, 1992: chs 8 and 9.

16 See reference 13: 196-7.

17 See reference 4: Brown M: 14

18 See reference 4: Brown M: 195 and reference 5: 366. 